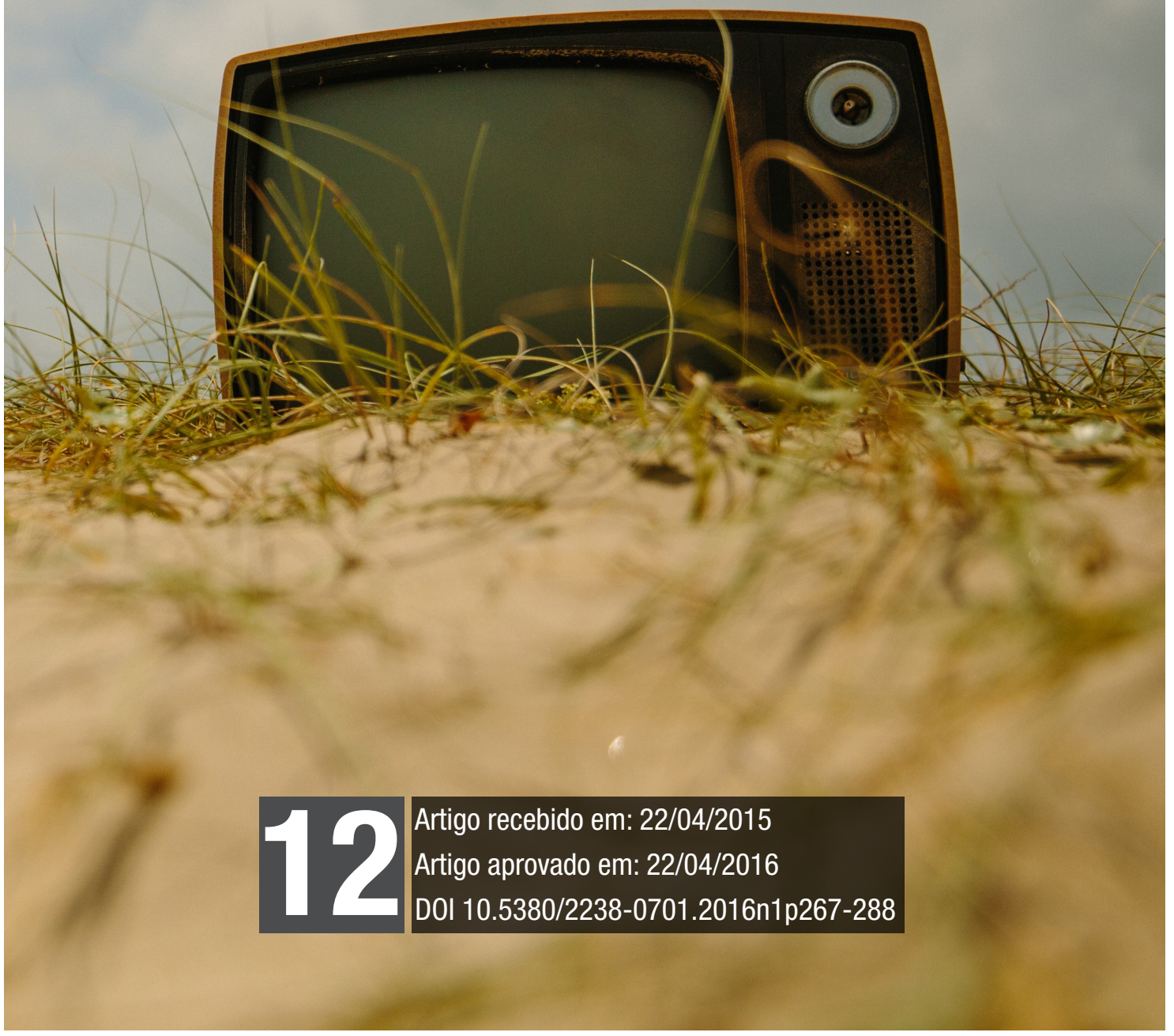


Televisão. Séries. Vanguarda. True Detective. HBO. 


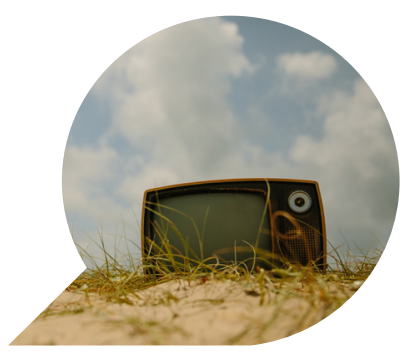

\section{$O$ vanguardismo cinematográfico transposto nas séries de televisão: um breve estudo de caso do canal HBO e da série True Detective}

The avant-garde cinema applied to a television series: a brief study of the $H B O$ channel and the True Detective series

El cine de avant-garde aplicado a series televisivas: una breve estudo del canal $\mathrm{HBO}$ $y$ de la serie True Detective

FERNANDA FRIEDRICH *

Resumo: O presente artigo visa enfatizar o processo de vanguardismo artístico em ficções seriadas da televisão. Destacando aspectos da vanguarda cinematográfica, o artigo debate o processo do cinema aplicado para a produção de séries de televisão. Para ilustrar o vanguardismo das ficções seriadas, o artigo ressalta o canal HBO conhecido por ousar nas séries que produz - e a série True Detective - uma ficção que propõe uma busca por uma linguagem inovadora.

Palavras-chave: Televisão; Séries; Vanguarda; True Detective; HBO.

* Doutoranda em Literatura na Universidade Federal de Santa Catarina (UFSC), mestre em Literatura Inglesa e graduada em Jornalismo pela mesma instituição. Lecionou na Universidade do Vale do Itajaí (Univali), na Universidade Regional de Blumenau (FURB) e atuou como professora substituta no curso de Cinema da UFSC. 
Abstract: The present work aims to emphasize the Avant-garde artistic process in the making of television series. Highlighting aspects of the cinema Avant-garde, the following article debates how cinema is influential to the production of television series. In order to show the Avant-garde in fictional series, this work stresses the HBO channel - known for experimenting on its productions - and the series True Detective - a fiction that is outlined by its pursuit for a breaking ground language.

Keywords: Television; Series; Avant-garde; True Detective; HBO.

Resumen: El objetivo del presente trabajo es analizar el proceso artístico de la Avant-garde en las series de televisión. El presente trabajo discute como el cinema influenció la producción de series de televisión, destacando los aspectos do cinema de Avant-garde. Para demostrar la presencia de la Avant-garde nas series fricciónales, analizamos el canal HBO - conocido por las experimentaciones en suyas producciones - y la serie True Detective - a ficción que está delineada por una busca por una lenguaje de vanguardia.

Palabras Clave: Televisión; Series; Avant-garde; True Detective; HBO. 


\section{Introdução}

"A morte da cinematografia é indispensável para que viva a arte cinematográfica"

Dziga Vertov

Não é novidade que o cinema de vanguarda trouxe uma nova perspectiva para o cinema convencional. De fato, é de senso comum dentro do campo das artes analisar os vanguardistas como aqueles que ousam primeiro, os que tomam a dianteira de novas tendências e mostram ao mundo novos olhares. No cinema, o vanguardismo segue o rumo do movimento nas outras artes. O campo contou e ainda conta - com cineastas de vanguarda como referenciais para outros do campo. Ainda que muitos filmes não tenham um interesse de provocar ou que possuam empenhos comerciais mais intensos do que os artísticos, a avant-garde do cinema continua influenciando todo o mundo cinematográfico.

Quando Dziga Vertov, precursor do cinema de vanguarda, afirmou que "até agora, violentávamos a câmera de filmar e obrigávamos a copiar o trabalho do nosso olho" (XAVIER, 1983, p. 41) ele expunha uma fraqueza do cinema até então. Vertov questionava o papel do filme e a função do cineasta dentro do sistema formado, ao passo em que ousava e incentivava mais produtores e diretores a pensarem o cinema fora do padrão que começava a ser criado. As indagações de Vertov foram além do papel de formar novos vanguardistas, chegando até os convencionais cineastas que até hoje continuam a utilizar referências da vanguarda da primeira parte do século passado.

Neste contexto de aplicar nas produções cinematográficas da atualidade os desafios propostos pela vanguarda há décadas atrás, outros formatos de audiovisual cada vez mais se apropriam deste discurso para suas próprias produções. A Music Television, conhecida como $\mathrm{MTV}^{1}$, considerada precursora no segmento televisivo, deu inicio nos anos 80 a um diferente movimento de experimentação na televisão. Para Charisse L'Pree, PHD em Identidade Social, a MTV pode ser considerada tanto de vanguarda como experimental ${ }^{2}$, já que

\footnotetext{
${ }^{1}$ A Music Television, MTV, fundada em agosto de 1981, é um canal de música, que lançou a moda dos videoclipes na televisão.

2 Trabalho entitulado "One world, One Image, One Channel: A history of MTV" One world, One Image, One Channel: A history of MTV", disponível em https://sites.google.com/site/charisselpree2/research/MIT-CMS/mtv/one-world-one-image-one-channel
} 
o canal foi feito e integrado de ideias que nunca haviam sido testadas e de técnicas ainda não estabelecidas. A MTV instituiu um ponto de partida para a televisão buscar o vanguardismo e hoje através das ficções seriadas, a busca continua. As séries de televisão se mostraram grandes aprendizes do cinema convencional ao longo dos últimos anos, apropriando-se do estilo cinematográfico visto nas grandes telas. Ainda assim, é necessário pontuar que com o crescimento da narrativa das séries de televisão houve o começo de uma busca pelo novo, por uma forma de fazer televisão diferenciada do que já existia. Contudo, movimentos vanguardistas ganharam uma nova face na $\mathrm{TV}$, trazendo à tona questionamentos, problemas e sugestões, além de destacar o potencial criativo e autoral do meio.

Antes de adentrar o assunto sobre o canal $\mathrm{HBO}$ e a série True Detective, alguns assuntos precisam ser abordados, como a origem do meio em questão. A televisão começou a aparecer nos lares estadunidenses no começo dos anos 40, mas devido à segunda guerra mundial, o meio ganhou notoriedade apenas no final da década. Com o retorno das tropas - e a prosperidade de ter vencido uma guerra - criaram-se nos Estados Unidos situações perfeitas para a disseminação do meio. As primeiras séries seguiam um modelo de Single Play, com câmera única, cenários fechados e gravações ao vivo, delimitadas pela tecnologia da época. Aos poucos as produções foram ganhando mais notoriedade, permitindo que a narrativa do cinema adentrasse as produções à medida que o formato similar a radionovela deixava de existir.

Ao longo das décadas de 50, 60 e 70, a televisão se estabeleceu não apenas em território norte americano, mas em volta do globo também. O meio passou a ser um disseminador de informações e de cultura, conquistando de vez a preferência do povo. Para João Rodolfo Prado "a televisão é uma ponte para o mundo exterior ao universo individual" (1973, p. 20) com a capacidade ilimitada de atingir novos horizontes e proporcionar novas experiências aos que tem acesso a ela. Diante da possibilidade de poder resgatar aspectos da cultura que seriam deixados de lado, tornando-os de eruditos a populares, surge uma nova esperança na utilização de um meio de massa. Como o próprio Jesus Martin Barbero defende, "o massivo foi gerado lentamente a partir do popular” (1997, p. 169) o que nos traz a conclusão que a combinação da qualidade com a exposição pode levar a obra 
cultural a uma posição mais relevante dentro da conjuntura social. Contudo, a característica simplificadora da televisão é apenas uma das suas tantas particularidades, já que o meio consegue tomar diversas formas, entre elas atuando como intermediador da arte popular, influenciando diretamente todos os meios que passam por ali e deixam a sua marca no formato.

Deste modo, autores, produtores e diretores começam a se desafiar dentro da televisão, tentando achar no meio uma nova forma de criar. A expressão "televisão de qualidade" que se popularizou na década de 1970 abriu caminho para a "televisão autoral" que apareceria com mais frequência depois da simbólica série Twin Peaks, de David Lynch e Mark Frost. Alguns autores chegam a falar de televisão pré e pós Twin Peaks, tamanha a relevância do trabalho de Lynch e Frost. A série gira em torno de um mistério, a morte da popular garota de 17 anos Laura Palmer. A trama que aparentemente é convencional, traz uma dinâmica incomum tanto na narrativa como na direção e fotografia da série. $\mathrm{O}$ suspense tem pitadas de surreal, com um texto diferentemente atrevido. Twin Peaks nos apresenta o quarto vermelho de Lynch, local em que o investigador da morte de Laura Palmer, Agente Cooper, tem epifanias sobre o caso. Na cena podemos ver um homem com nanismo, uma sósia da garota e o próprio Cooper, com diálogos em uma língua bizarra em um contexto perturbador que marcaria a filmografia de Lynch para sempre. E esta ocorreu na televisão, não no cinema.

Em termos comercias, podemos avaliar a entrada da televisão à cabo no mercado estadunidense também como um agente impulsionador da busca por novidades dentro das narrativas televisivas. Desta forma, o comercial acabou como aliado da forma autoral, permitindo que diretores como Lynch tivessem um espaço mais aberto para experimentar nas telinhas. Como o propósito deste artigo é analisar os movimentos de vanguarda na produção de ficções seriadas televisivas, é importante destacar que a partir de Twin Peaks a qualidade dos conteúdos produzidos aderiu uma constante positiva. A busca pela qualidade autoral do cinema faz com que a ficção televisiva tenha se aproximado extraordinariamente do padrão cinematográfico e já esteja inclusive o desafiando, apresentando obras bem além do esperado para o meio. Alguns creditam o crescimento atual do gênero das séries televisivas à competição do mercado contra filmes, outros à padronização da qualidade do audiovisual. Independente das 
razões, observamos que o conteúdo seriado se aprimorou em busca de uma qualidade cinematográfica.

Em sua jornada de crescimento, o conteúdo seriado para televisão tem apresentado diversas adaptações de estilo, narrativa, entre outros, antes presentes apenas no meio cinematográfico. A apropriação de características pertencentes ao mundo fílmico sinalizam uma aproximação das limitações do cinema padrão e a busca pelo cinema experimental como inspiração para uma vanguarda televisiva. De tal modo, o presente artigo apresentará a temática da apropriação de aspectos da vanguarda cinematográfica para a produção do conteúdo de séries televisivas, enfatizando a forma que a mesma está sendo feita e as consequências desta aproximação. Para exemplificar a utilização e a criação de referências vanguardistas, a série True Detective ${ }^{3}$, exibida no começo de 2014, será analisada, referenciando propostas e métodos utilizados nas artes - especialmente o cinema - de vanguarda.

\section{A televisão e a influência da vanguarda}

Quando Jean Vigo afirma que "O cinema sofre mais de um vício de pensamento do que da ausência de todo e qualquer pensamento" (ROCHA, 1981, p. 114) ele destaca a falta de ousadia como um problema maior do que a falta de criatividade do âmbito audiovisual. Por mais que exista um pensamento, uma criação, a semelhança com um estilo, um padrão imposto pelos produtores permanece sendo uma ameaça à qualidade do que é produzido. Na televisão podemos observar uma tendência semelhante. Durante muitos anos a busca por formatos inovadores foi esquecida perante ao ideal de produzir o mais do mesmo, o garantido que agradava aos interesses comerciais. A busca pelo novo só começou a transparecer quando a TV já estava estabilizada.

Como um meio dependente economicamente, a televisão ainda se mantém fortemente atrelada a números relacionados a vendas. A independência total da televisão é ainda utópica, mas já temos sinalizações da mesma em iniciativas precursoras, como o Netflix ${ }^{4}$. Todavia, o vínculo com anunciantes ainda é dominante e este fator acaba derivando muitas críticas quanto ao conteúdo oferecido. Para agradar a todos, há uma variedade muito grande de conteúdos, a maioria

\footnotetext{
${ }^{3}$ True Detective é uma série baseada na peça The King in Yellow, de Robert W. Chambers.

${ }^{4}$ Netflix é um serviço de Televisão pela Internet que disponibiliza um vasto catálogo de filmes e séries. 0 serviço já tem cerca de 44 milhões de assinantes em mais de 40 países.
} 
explorada de forma rasa, visando a quantidade mais do que a qualidade. No livro "Cultura das Mídia”, Lúcia Santaella aponta que "a TV se caracteriza como uma mídia das mídias, isto é, tem um caráter antropofágico. Ela absorve e devora todas as outras mídias e formas de cultura" (SANTAELLA, 2000, p. 42). Assim, a autora destaca o grande potencial da televisão em todos seus âmbitos - tanto de recepção como de reprodução.

Contudo, aprofundamos no exemplo de como o cinema influenciou toda a produção para a televisão. Programas que nunca passarão - nem passaram - pelas telas de cinema, adquirirem através de inspiração e de um certo tipo de osmose a qualidade que antes era reservada a produtos de cinema artístico. A qualidade da produção para televisão, seja em aspectos narrativos ou tantos outros, ganhou muito com o advento da mistura de referências do meio, que inclusive trouxe o cinema vanguardista a ser exposto através de um meio de massa, chegando a um público mais amplo. Com a possibilidade do acesso mesmo que escasso à vanguarda do audiovisual, há um campo maior para a inspiração das narrativas tradicionais nas ousadas premissas dos filmes vanguardistas.

John Ellis menciona diferenças entre ambos os meios, denotando o que se sobressai entre as suas semelhanças e desavenças. De diferenças de recepção, como a experiência causada ao expectador do cinema contrastada com o modo mais simples da televisão, até a forma em que explora os dramas de uma forma serial e sequencial, o autor projeta os meios como diferentes campos que entram em fusão em determinados pontos. No caso, a televisão "se espelha no cinema para prover certos tipos de inovação" (ELLIS, 1992, p. 226). Essa inspiração, é a que nos leva encontrar nas novas produções traços do cinema vanguardista, que trazem a um meio popular um novo olhar.

Voltando a nossa atenção ao tema principal deste artigo, podemos considerar a influência do cinema de vanguarda na televisão como um passo em direção a uma democratização da informação, repensando posturas e, principalmente, fugindo do formato óbvio. Em "O Discurso Cinematográfico", Ismail Xavier levanta o debate sobre o retrato do real pela vanguarda. $\mathrm{Na}$ discussão, há uma convergência de visões que classificam o discurso vanguardista em várias perspectivas. Entre elas, há um ponto que destaca o uso do real de forma abstrata, obtendo, devido a sua realidade, uma camada mais 
verdadeira da representação do nosso mundo. Não obstante, Xavier nos leva à conclusão que "todo e qualquer realismo é sempre uma questão de ponto de vista, e envolve a mobilização de uma ideologia cuja perspectiva diante do real legitima ou condena certo método de construção artística" (XAVIER, 2005, p. 100). Logo, tomando a mobilização vanguardista como base, o leque de possibilidades de expressar o real que a televisão possui tem seu potencial multiplicado devido ao meio em que está inserido.

A possibilidade de experimentar através de influências de vanguardas assume um novo e importante papel dentro deste grande meio de massas. Há uma ligação com o cinema social que pode ser criada a partir da experimentação e da recriação de tendências fixas. Jean Vigo questiona o papel do filme social e coloca: "A nossa indiferença, que nos permite aceitar todas as monstruosidades dos homens abandonados na terra é submetida a uma dura prova quando não aguentamos a visão no <<écran $>>$ e um olho e mulher cortado em dois por uma lamina de barba”. (ROCHA, 1981, p. 115).

Vigo questiona o nossa interpretação e nossa recepção ao que é mostrado, evidenciando a importância de experimentos vanguardistas, como o de Luís Buñuel em Un Chien Andalou, para levantar perguntas sobre o real conteúdo dos filmes. Aplicado diretamente às séries de televisão, notamos a importância de uma estética ousada e de uma narrativa permissiva que não imponha tantas limitações aos que assistem. $\mathrm{O}$ contato com uma série sem tantas amarras narrativas convencionais traz uma nova perspectiva sobre o conteúdo que está no ar, com uma diferente forma do espectador se relacionar com a trama através de um formato inovador.

Xavier pontua nosso papel de público como pessoas que devem elevar a sua "sensibilidade de modo a superar a 'leitura convencional' da imagem e conseguir ver, para além do evento imediato focalizado, a imensa orquestração do organismo natural e a expressão do estado da alma" (XAVIER, 2005, p. 103-4). O autor faz uma ressalva importante ao considerar que ao ter uma interpretação mais ampla do conteúdo conseguimos extrair signos mais complexos e mais pessoais de situações mais generalizadas, potencializando o alcance do cinema. Com uma extensão mais abrangente, há uma democratização no que é exposto, já que há uma relação pessoal íntima com cada um dos que lê a informação passada. Por conseguinte, "uma relação 
sensorial mais integral com o mundo e a apreensão de sua 'poesia' tornar-se-ia possível graças à nova arte e seu poder de purificação do olhar" (XAVIER, 2005, p. 104).

\section{O experimentalismo no canal $\mathrm{HBO}$}

Ao mencionar os aspectos de vanguarda televisiva que a série True Detective apresenta é interessante apresentar o canal em que a mesma é veiculada. O HBO (Home Box Office) é um canal estadunidense, privado, de filmes, presente via televisão paga em mais de 60 países, sendo um deles o Brasil. Apesar da grade de programação do canal ser composta majoritariamente por filmes de grandes estúdios, nas últimas duas décadas o canal começou a se destacar pela produção de séries e filmes originais, produzidos para serem exibidos exclusivamente no canal. Entre os nomes mais famosos citamos The Wire (2002-2008) ${ }^{5}$; The Sopranos (1999-2007) ${ }^{6}$; Six Feet Under (2001-2005) ${ }^{7}$; Sex and The City (1998-2004) $)^{8}$ e atual Game of Thrones (2011-atual) ${ }^{9}$.

As produções da $\mathrm{HBO}$ se destacaram ao longo dos anos pela originalidade, narrativa, cinematografia e ousadia nos temas tratados nas séries e filmes. Sally Munt destaca a capacidade do canal de produzir um novo estilo de drama crítico colocando a HBO como:

(R)econhecível pela grande qualidade nas produções, inovações nos roteiros, estrutura original e complexa de trama, sexo e violência explícitos, tendências ideológicas liberais/democráticas, narrativa e caracterização inteligente e por retratar temas políticos contemporâneos de forma séria. (MUNT, 2008, p. 67)

Munt ainda enfatiza em seu estudo que a HBO trabalha em suas séries e filmes originais aspectos "experimentais e avant-garde na estrutura formal” (MUNT, 2008, p. 67). Para Munt, o canal ousa e possibilita uma nova tendência para o mercado fílmico, já que com a sua visão criativa e inovadora consegue ousar mais do que os estúdios tra-

\footnotetext{
${ }^{5}$ Série sobre rede de tráfico de drogas em Baltimore, Estados Unidos, pela visão dos traficantes. ${ }^{6} \mathrm{~A}$ série narra a máfia italiana em Nova Jersey, Estados Unidos. Com fortes cenas de violência.

${ }^{7}$ Série mistura o drama com o humor negro no retrato do cotidiano de uma família com dramas homossexuais.

${ }^{8}$ Série com protagonistas femininas em que há uma forte abordagem sobre sexo.

${ }^{9}$ Série que retrata a briga por poder em reinos fictícios, com traços de incesto e forte violência.
} 
dicionais. Seguindo a linha de Munt, a HBO serviu como inspiração para outros canais também começarem a produzir um conteúdo mais ousado e fora do tradicional. Do canal AMC, com as séries Breaking Bad (2008-2013) $)^{10}$ e The Walking Dead (2010-atual), às produções originais e independentes do Netflix, há uma tentativa maior em buscar inovações no meio televisivo, respeitando a diversidade do público e apresentando alternativas ao conteúdo usual da televisão.

\section{O vanguardismo em True Detective}

True Detective é uma série produzida especialmente para o canal HBO que estreou em Janeiro de 2014 e foi exibida logo em diversos países, entre eles o Brasil. A trama conta a história de dois detetives que em 2012 são interrogados sobre uma investigação que fizeram em 1995. Nos primeiros cinco dos oito episódios (de aproximadamente uma hora cada), a narrativa é alternada constantemente entre o passado e o presente, da época em que Martin Hart (Woody Harrelson) e Rustin Cohle (Matthew McConaughey) investigaram crimes que levaram a prisão de um assassino serial ao dia em que são interrogados e investigados como possíveis responsáveis pelos crimes então resolvidos. A partir do quinto episódio começamos acompanhar a história de uma forma narrativa mais convencional, com o presente como tempo apresentado e com o passado sendo proporcionado apenas em flashbacks. A narrativa quebrada está presente durante toda a série, porém principalmente nos primeiros episódios ela é colocada de forma com que não é claro o tempo que estamos situados.

Optou-se por uma questão de objetividade analisar primeiramente de uma forma concisa a vinheta da série como uma representação do conteúdo total da mesma. Ao observá-la, podemos ter uma visão mais clara dos referenciais que aparecem durante a primeira temporada. Entre símbolos religiosos e ligações ao paganismo, a própria trajetória dos protagonistas e da investigação é referenciada na vinheta de True Detective. No estilo da vinheta, vemos imagens projetadas nas sombras dos personagens, alguns se sobressaindo do espectro. Inicialmente, as imagens são urbanas e lentamente aparentam ser mais rurais.

\footnotetext{
${ }^{10}$ Série que mostra a transformação de um homem comum em um grande traficante de metanfetamina.
} 
Ao longo da vinheta vemos cada vez mais as referências religiosas, que ligam a símbolos de fé e de luxúria. A fé, a religião, o sobrenatural, o pecado e a punição, são temas centrais na série, retratados na vinheta de formas alegórica.

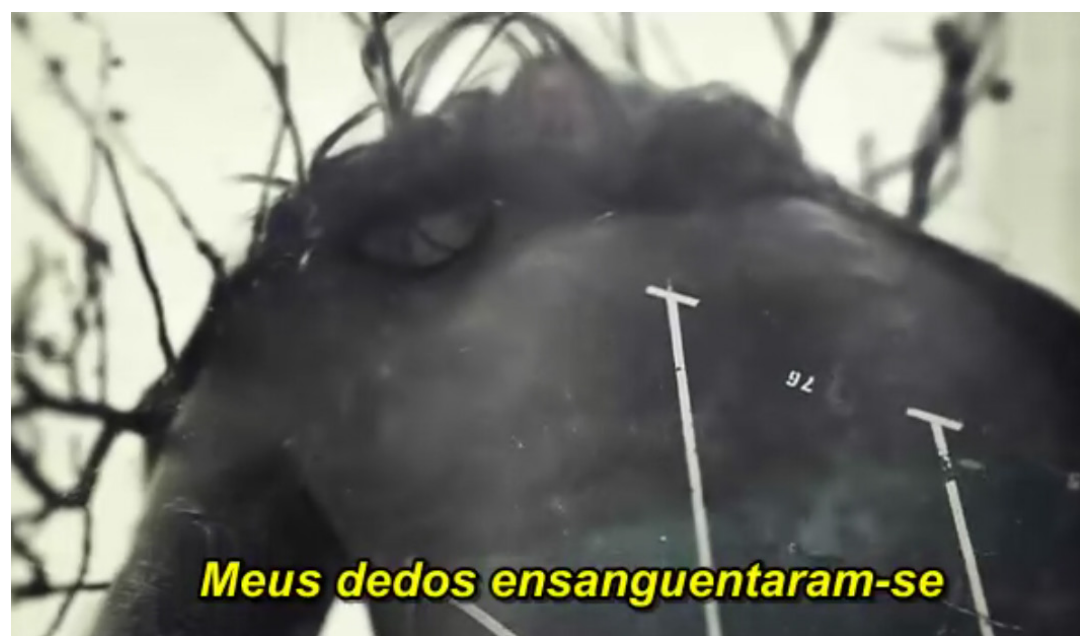

Figura 1 - Vinheta True Detective, 2014, Cary Joji Fukunaga. Foto: Printscreen quadro 39s.

Os personagens principais Martin e Rustin aparecerem algumas vezes como sombras com projeções. Mais perto do fim, suas figuras abrigam reflexos mais sombrios, com uma transformação em chamas.

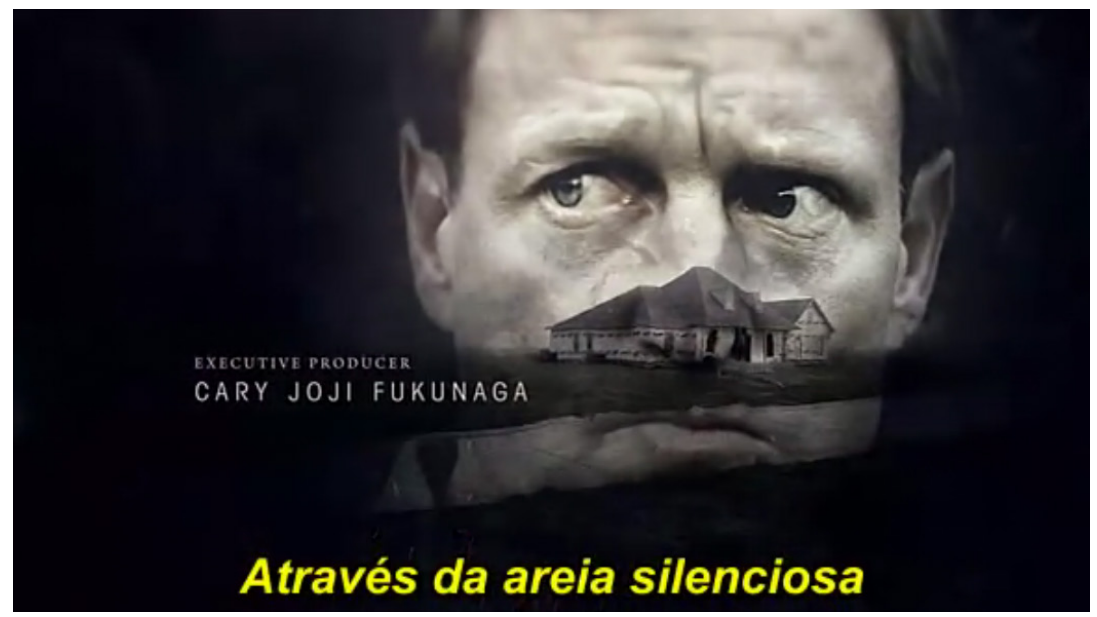

Figura 2 - Vinheta True Detective, 2014, Cary Joji Fukunaga. Foto: Printscreen quadro 70s. 


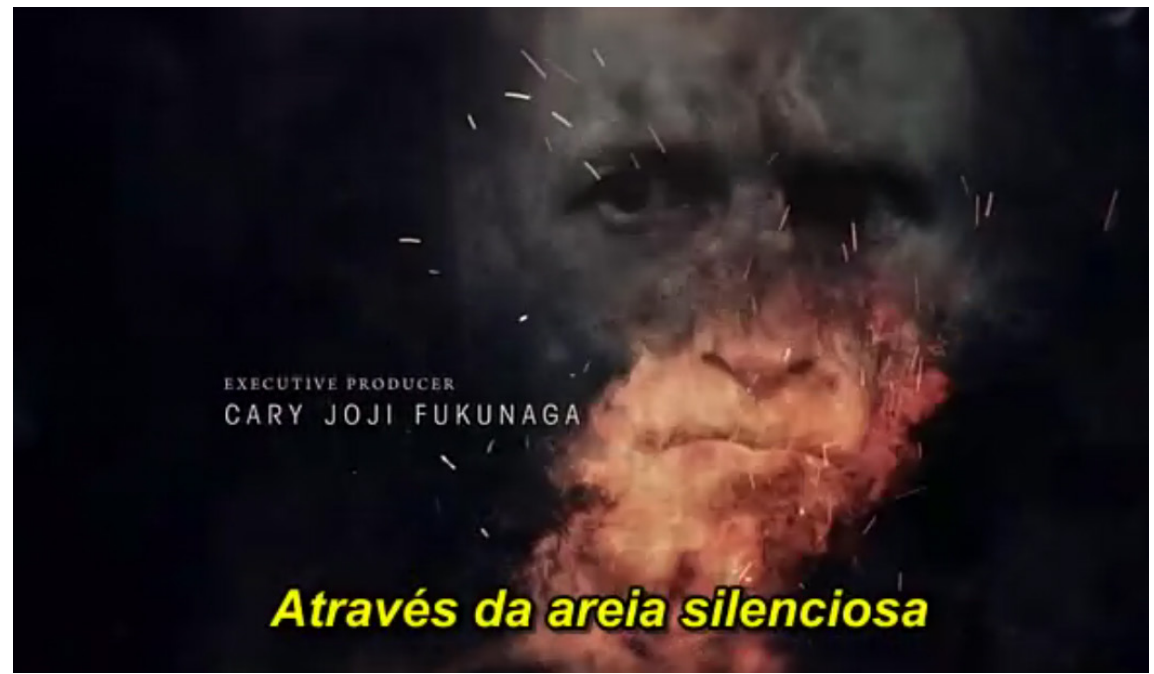

Figura 3 - Vinheta True Detective, 2014, Cary Joji Fukunaga. Foto: Printscreen quadro 72s.

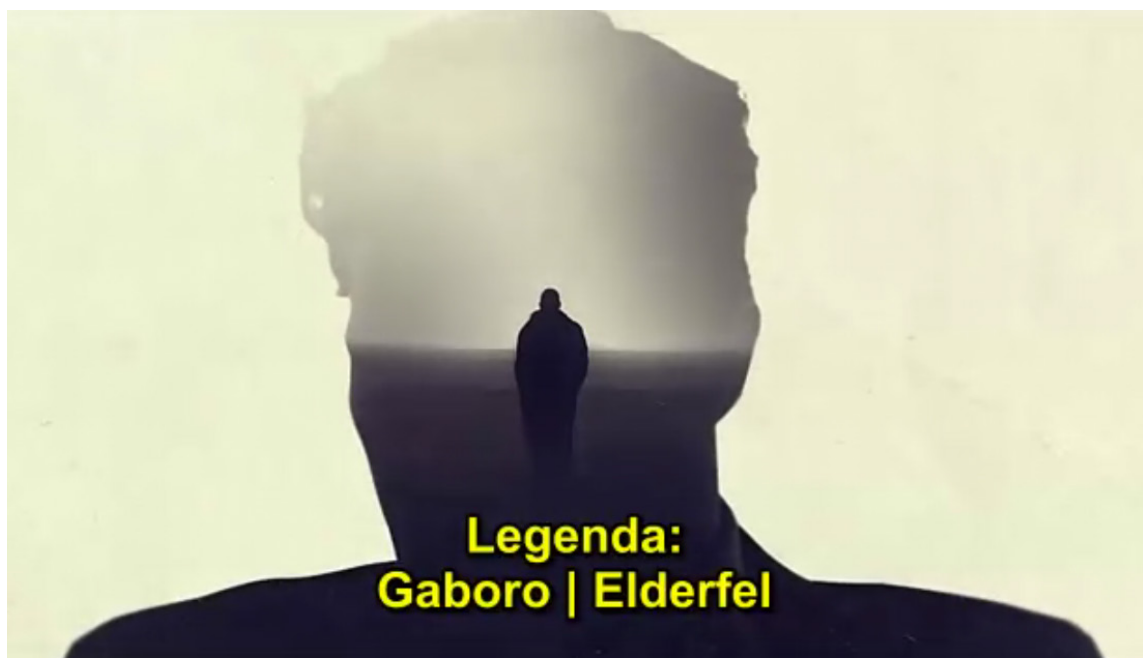

Figura 4 - Vinheta True Detective, 2014, Cary Joji Fukunaga. Foto: Printscreen quadro 45s. 


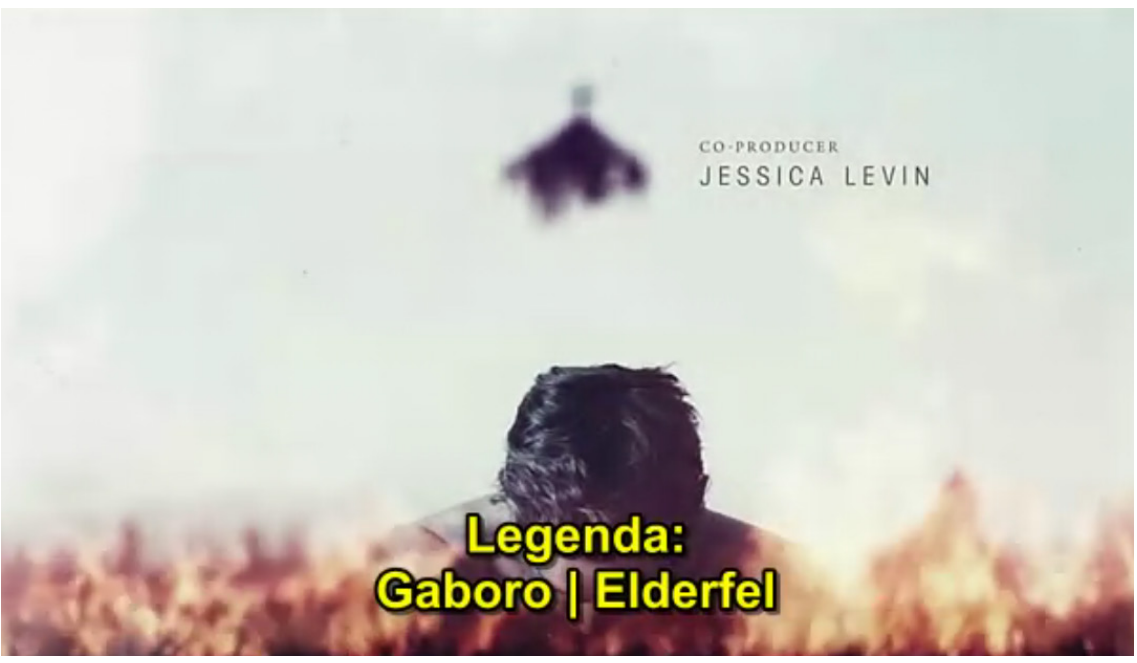

Figura 5 - Vinheta True Detective, 2014, Cary Joji Fukunaga. Foto: Printscreen quadro 47s.

A transformação da vinheta antecipa o que ocorre na série, onde aos poucos uma investigação simples começa a ter elementos que ligam o mundo real a um mundo imaginário, em que a realidade começa a ser questionada diante de crenças e magias. O real não tem o mesmo peso na narrativa da série que tinha no começo, assim como a clareza da vinheta no seu começo se diferencia do seu final. A transposição de imagens combinadas à música criam uma sensibilidade maior para o que virá na série. Se prestarmos atenção, notamos os principais conflitos dos personagens introduzidos na vinheta. A casa na sombra de Martin - um homem que convive com a culpa de trair a sua família -, o homem solitário na sombra de Rustin - o detetive perdeu a filha e a esposa - introduz os problemas dos protagonistas. A utilização da vinheta como uma forma de localizar a narrativa não é notada imediatamente. É algo que exige conhecimento da narrativa para o entendimento da mesma. Ainda assim, a interpretação é livre, é pessoal, afinal "a compreensão do significado do filme é tarefa a ser efetuada pelo receptor [...] é o espectador que decodifica as cine-frases e percebe seu significado" (MACHADO, 1989, p. 152).

Nota-se uma tendência vanguardista no uso da vinheta como algo além do estético, da óbvia apresentação dos nomes da equipe técnica da série. Há uma utilização artística do espaço para introduzir a narrativa de uma forma enigmática, a apresentação do conteúdo realmente toma a forma de introdução, ao levar a vinheta para um 
nível narrativo bem mais avançado que a forma plenamente estética com que a mesma geralmente é apresentada.

Entre a abstração visual puramente linear (e um jogo de sombras e reflexos é como um jogo de linhas) e o filme de fundamento psicológico que relata o desenvolvimento de uma história, dramática ou não, há lugar para um esforço em direção ao cinema verdadeiro (ARTAUD, 1995, p. 159)

Entre o papel comercial da televisão e a arte, a vinheta, como um reflexo da série, busca uma linguagem mais complexa, mais artística, menos óbvia, mas que ainda caiba no meio televisivo. Ao analisar o conteúdo dos episódios, verificamos um padrão semelhante, o que nos traz à busca mencionada em "Linguagem e Vida", de Antonin Artaud (1995). Observamos ao longo da temporada uma confusão temporal e de sentimentos, saindo da zona de conforto tradicional das narrativas apresentadas na televisão. Como Ismail Xavier aponta para buscar o novo "[é] preciso introduzir a ruptura no próprio nível de estruturação das imagens, no nível da construção do espaço, quebrando a tranquilidade do olhar submisso às regras" (XAVIER, 2005, p. 113). O rompimento do padrão possibilita chegar a um formato diferente, com a obra alcançando um novo patamar, um esboço de vanguarda. Assim, podemos inclusive relacionar sequências fílmicas da série com a obra expressionista, já que em muitas a incerteza espacial e temporal são o que regem as mesmas.

Logo na primeira cena de True Detective, observamos através de uma fotografia escura e sem muito foco o que aparentemente é alguém colocando fogo em um campo. Na próxima cena, já somos jogados em um interrogatório que, de acordo com uma legenda informativa, acontece no dia $1^{\circ}$ de maio de 2012. Na continuidade, não temos nenhuma referência à primeira cena mostrada. Ao longo da narrativa e dos episódios podemos relacionar aquele início com um crime que ocorreu, mas ainda não há evidência sequencial que localize exatamente o que acontece. A cena permite propositalmente uma interpretação livre no começo da série, que pode ter significados ou não, depende das conclusões que o expectador tira. Contudo, o modelo de edição da série segue de certa forma a montagem apresentada na vinheta - nem todos os elementos fazem um sentido sequencial, onde a obviedade e a continuidade do cinema padrão abre espaço para as coincidências do cinema experimental - ou, neste caso, televisão autoral. 
Quebras de narrativa fazem parte do estilo desconstruído de narração que a série apresenta. Identificamos na tendência do expressionismo cinematográfico uma descrição comparável ao que acontece na narrativa da série, quando o estilo fílmico é definido com a quebra da "continuidade do espaço, ao instituir suas dobras e suas sombras, [como se] drama expressionista [quisesse] reintroduzir as marcas do invisível, desmascarar o mundo visível" (XAVIER, 2005, p. 102). $\mathrm{Na}$ série uma sequência não precisa fazer parte de uma continuidade para ter significação. A quebra de informações ou a forma com que as mesmas não são claramente identificadas aparecem com uma qualidade narrativa que permite o invisível ser visto, validando pequenos gestos e trazendo múltiplas interpretações do que poderia ser descartado se a sequência obedecesse às regras mais padronizadas da edição Griffitiana ${ }^{11}$.

O expressionismo conta com a identificação do herói pelo público, com a quebra da expectativa como uma forma de tornar aquilo mais próximo de quem assiste, como se o filme exteriorizasse a visão interior, possível com a quebra do correto concreto. Há uma aplicação das visões do entorno, fugindo do realismo absoluto em busca da imaginação particular.

Trabalhando contra a superfície clara, a decupagem clara, contra o gesto natural e o grama inteligível segundo leis naturais, a obra expressionista privilegia o comportamento obscuro, de seres humanos que se deslocam estranhamente num espaço cheio de dobras e, desta forma , instaura um espaço dramático regulado por forças distintas (XAVIER, 2005, p. 101).

Próximo ao minuto cinco do primeiro episódio há a interação entre os detetives Martin e Rustin chegando à cena de um crime. Antes disso vimos os personagens separados, sendo questionados no que seria o presente sobre os acontecimentos no entorno da investigação. Até então, na nossa timeline de acontecimentos existem mais fatos soltos do que acontecimentos propriamente amarrados em uma continuidade. As dobras fazem com que seja possível para o público observar mais atentamente aos comportamentos, medindo os significados mais por seus signos em si do que pela localização temporal.

$\mathrm{Na}$ busca de um retrato menos objetivo e mais confuso do real, a

\footnotetext{
${ }^{11}$ Edição Grifithiana é baseada em no conceito de continuidade, disseminado por W. Griffith ,
} considerado um dos pais da montagem cinematográfica. 
narrativa de True Detective segue outros padrões baseados em outros movimentos vanguardistas além do expressionismo. Com protagonistas densos, complexos e inconstantes, há uma fuga do padrão de herói. Com isso, a série novamente acaba criando uma possibilidade de aproximação entre o público e a história maior. O perfeito perde para os defeitos, um espelho que destaca vaidades é aberto e o público se enxerga muito mais na ruptura de um padrão temporal e narrativo do que na organização de uma história que busca o verossímil. É possível identificar também traços da vanguarda do cinema estrutural, já que sabemos que o filme deste gênero busca:

Através da montagem, produzir um padrão de relações capaz de remeter a platéia a uma discussão sobre a organização da linguagem do cinema e suas relações com o discurso falado [...] o novo filme de vanguarda busca a apresentação de uma estrutura simples, capaz de construir uma metáfora para certas operações de consciência e especialmente para atividade de percepção. Neste sentido, culmina, num projeto de tendência intelectual, a inclinação geral da vanguarda americana para a proposição de um cinema voltado para a subjetividade e para a projeção dos 'mundos interiores' na tela (XAVIER, 2005, p. 123-4).

Existe uma intensificação nos conflitos internos que acontece com a estruturação dos personagens como peças em um tabuleiro. Dentro dos seus conflitos os personagens criam motivações que instituem uma maior identificação do ser complexo que o personagem se torna. Os heróis da série são personagens misteriosos que alternam as suas personalidades ao longo da trama contada em aproximadamente oito horas. Martin Hart oscila em seu papel de mulherengo e funcionário público incompetente para um amigo leal, marido amoroso e um detetive dedicado. Já Rustin passa de um drogado, com problemas pessoais para um detetive disposto a arriscar sua vida pelo trabalho, provando ser um dos mais competentes já vistos no departamento (de tão dedicado é chamado de "Tax Man"12 pelos colegas). Estas mudanças sinalizadas ao longo da vinheta e transpostas na narrativa da série acontecem ao longo de toda temporada. O herói vilanizado ou o vilão heroico são muito utilizados no meio fílmico fora do eixo comercial. Com uma aproximação mais complexa, este

12 “Tax Man” (Homem dos Impostos) é o apelido que Rustin ganha por ser muito correto em seu trabalho. Em tradução livre, seria similar a gíria brasileira "Professor Caxias". 
tipo de abordagem tende a explorar mais a fundo a psique dos protagonistas tornando a narrativa mais adversa.

Enfim, como a vinheta antecipa, há uma transição de espaço entre o claro e o escuro, o bom e o ruim, com o dualismo entre os personagens e o sofrimento aparecendo ao longo da narrativa. Se há a antecipação da penalização com a presença do fogo na vinheta, na série pequenos detalhes fazem com que o dualismo esteja sempre presente. Quando acompanhamos a narrativa pelos olhos de Rustin, observamos alguns devaneios que não ficam claros serem alucinações ou efeitos sobrenaturais. Como Rustin tem um histórico com drogas, temos uma base que nos leva a crer que há uma máscara fantasiosa no que enxergamos. Porém, como a narrativa trata de fanatismo religioso e paganismo, a dúvida sobre o sobrenatural é vívida.

\section{Cosiderações finais}

Para Sônia Rodrigues, "as séries são a narrativa do século XXI. Elas são para o nosso século o que o romance foi para o século XIX e o cinema para o século XX” (RODRIGUES, 2014, p. 9). Ainda assim, parece ser complicado falar de experimentalismo em televisão, pelo estereótipo realista que o meio tem e a imagem antirrealista que o vanguardismo apresenta. Seria a vanguarda de todo irreal e a televisão de todo realista?

Falar das propostas de vanguarda significa falar de uma estética que, a rigor, somente é antirrealista [sic] porque vista por olhos enquadrados na perspectiva constituída da Renascença ou porque, no plano narrativo, julgada com critérios de uma narração linear cronológica, dominada pela lógica do senso comum (XAVIER, 2005, p. 100).

Xavier desafia a lógica do senso comum, buscando um olhar que veja além das molduras fixas, que separem o real do cronológico ou do sequencial. É possível que por trás da busca por um novo formato esteja uma procura por uma aproximação mais convergente da realidade. A descaracterização da representação do real de forma clara, objetiva e fácil para uma forma muito mais complexa de abranger os defeitos da realidade. Talvez a ficção para a televisão aparentemente não tenha o potencial para ser tão inovadora quanto as vanguardas fílmicas proclamam ser. No entanto, as aparências enganam - por ser 
o meio que junta diversas artes, diversos públicos, como Santaella defende, o potencial da televisão muitas vezes é ignorado mediante a estereótipos construídos a partir da sua origem comercial.

Comparar televisão e cinema pode, ao mesmo tempo, ser útil e ser um desastre. É necessário entender que com os meios diferentes, as limitações, as possibilidades e principalmente as aproximações tendem a tomar diferentes caminhos. É possível existir um movimento de vanguarda que não seja idêntico aos anteriores de outras expressões artísticas e que perante os olhos das artes tenha diferentes limitações, mas que dentro do seu próprio meio seja revolucionário. Notamos que os trabalhos exibidos na HBO - incluindo True Detective - dão vida a uma crescente etapa na produção de ficção autoral para a televisão. Tal movimento poderá ser mais surrealista no futuro, trazendo o vanguardismo e o experimentalismo ainda mais incisivamente para a televisão. Podemos concluir que na união do vanguardismo com a televisão há um crescente potencial em trazer novidades à um meio de massa, com as séries elevando a experiência televisiva, criando uma aproximação à experiência artística, dando continuidade ao espírito vanguardista da TV revelado nos anos 80 através da MTV.

\section{REFERÊNCIAS}

ELLIS, John. Visible Fictions: Cinema, Television, Vídeo. London: Routledge, 1982.

SANTAELLA, Lúcia. Cultura das mídias. Sao Paulo: Experimento, 2000.

SHOHAT, Ella; STAM, Robert. Crítica da imagem eurocêntrica: multiculturalismo e representação. São Paulo, SP: Cosac \& Naify Edições, 2006.

MACHADO, Arlindo (org.). Made in Brazil: Três décadas do vídeo Brasileiro. São Paulo: Iluminuras/ Itaú Cultural, 2007.

MARTIN B. Jesus. Dos meios as mediacoes: comunicacao, cultura e hegemonia. 1.ed. Rio de Janeiro: Ed. UFRJ, 1987. 369p

MUNT, Sally. The cultural politics of shame. Hamshire: Ashgate, 2008. 
PRADO, Joao Rodolfo do. TV: Quem vê quem. Rio de Janeiro: Eldorado, 1973. 260p.

RODRIGUES, Sônia. Como escrever séries: roteiro a partir dos maiores sucessos da TV. São Paulo: Aleph, 2014.

VERTOV, Dziga. Dziga Vertov. Vasco Granja. Lisboa: Horizonte, 1981.

VIGO, Jean. Jean Vigo. Lisboa: Horizonte, 1981.

XAVIER, Ismail (org.). A experiência do cinema - Antologia. Rio de Janeiro: Graal/Embrafilme, 1983.

Ismail. A opacidade e a transparência. São Paulo: Paulo: Paz e Terra, 2005.

TRUE DETECTIVE. Direção de Cary Joji Fukunaga. Roteiro: Nic Pizzolatto. 2014. Son., color. Primeira temporada. 


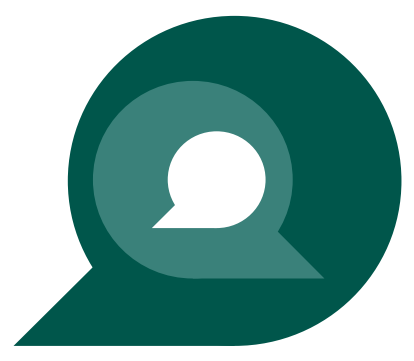

